significant amounts of GHG production it leads more particularly to the transfer in the local arable land of undigested carbon, enriched in nitrogen and other nutrients. Wool, leather and skins also help to meet the needs of the farmer and provide livelihoods. Draft animals have always played a major role in tillage and other soil cultivation techniques and in the transport of goods and people. The second group of functions is economic. The sale of animal products provides income and livestock keeping is a means of savings. In many regions, especially in OECD countries, income became the main and most of the time unique function of animal production. Livestock sub-sectors contribute to the economy in the territories, from local to global scale, through several up and downstream activities out of the farm. Human dimensions of livestock are another significant group of functions. In many locations, raising animals is a great and highly recognized job. The size, nature, composition and quality of the herd and grassland areas give information about the social status of the owners. Donations of animals for baptisms, weddings, inheritances and other celebrations are still common in many societies. From an environmental point of view, animal production contributed significantly to build landscapes and manage natural resources in all the parts of the tropical, temperate and cold areas.

Facing the increasing demand on animal products linked to the current process of urbanization and middle class development, the sustainable scenarios denote the necessity to increase production but, at the same time, the high need to reduce the negative impacts. Considering past experiences, particularly along the environmental and social impacts, we can logically imagine that the models of the future will inevitably have to consider the diversity of the ecological, social and economic contexts. Rather than radically change the current local scale models, the ways toward sustainability require progressively integrating the relevant factors within ecological and human dimensions. This implies including ecological and human sciences in R\&D processes in order to focus on the resilience of local societies and ecosystems and on the knowledge and capacity building needed to improve the sustainable efficiency of the systems.

Although local system management has to evolve towards a better integration of global and local stakes, research practices also have to progress. After years of pluridisciplinary approaches where several disciplines co-existed in the research process, the multidisciplinary approach has become an improving method joining several disciplines on a same research subject. Further, the interdisciplinary approach tended to integrate tools and methods. The next step is the trans-disciplinary approach where research integration is dynamic and holistic, from the definition of research subjects to the understanding of its complexity. Another requirement of this transdisciplinarity is the commitment of all the actors involved in animal production at a regional scale, including policymakers and stakeholders of the lobbies counteracting animal production.

Local approaches, the "systemic" capability developed by many researchers in both "hard" as well as in "soft" systems, offer the opportunity to effectively integrate innovant global methods such as LCA life cycle analysis in livestock value chains and beyond to investigate concepts and tools and to evaluate frontiers of sustainable efficiency.

Appropriate methods including local knowledge and co-designing of innovations are highly needed given the rising issues that have developed around systems approaches and the responses they can provide to address the complex issues raised by livestock breeding.

To accompany the livestock system changes, a challenge ahead is that of the nature and development of cognitive systems. These are fundamental to any approach in the integrative and systemic understanding of livestock systems. On these new fields, a broad collaborative partnership has to take place between global and local societies and research systems.

\title{
Modelling crop-livestock integration systems at a farm scale in a Highland region of Madagascar: a conceptual model
}

\author{
Stéphanie Alvarez ${ }^{\dagger}$, Paulo Salgado, Jonathan Vayssières, François Guerrin, Pablo Tittonell, \\ François Bocquier and Emmanuel Tillard
}

CIRAD, Pôle élevage, La Réunion, France

\section{Introduction}

The Malagasy Highland region of Vakinankaratra $\left(19^{\circ} 51^{\prime} \mathrm{S} ; 47^{\circ} 01^{\prime} \mathrm{E}\right)$ is the heart of the Madagascar dairy basin and generates $90 \%$ of the national dairy production. Farms are based on diverse crop rotations, where rice is the main crop, and livestock activities (dairy cows, zebus, pigs, poultry, etc.). Milk is produced by a multitude of smallholders (with on average less than five cows) usually feeding animals with crop residues and natural vegetation. This region suffers serious erosion problems and soil fertility degradation (Douzet et al., 2008) which has increased with crop-cover and over-use of land for agriculture and livestock feeding. In these complex traditional farming systems, integrative and interdisciplinary modelling tools are needed to better understand crop-livestock interactions and identifying a compromise between resources allocation for livestock production and soil fertility improvement. The purpose of this work was to build a biophysical whole-farm computer model (milk and crop yields) for simulating, on a farm scale, the various flows of biomass occurring between different compartments (cattle, crops, stocks of organic plant material, soil, organic fertilizers, etc.) in these mixed farming systems.

\footnotetext{
${ }^{\dagger}$ E-mail: stephanie.alvarez@cirad.fr
} 


\section{Modelling}

Modelling crop-livestock systems in tropical areas is still considereably under-developed. The objective was to assess the impact of changes in biomass allocation (animal feeding vs mulch) on production (milk production, crop yield) and the environment (carbon sequestration, nitrogen availability, and soil fertility). The general framework explained in Thornton and Herrerro (2001) for the integration of detailed biophysical livestock sub-models (herd demographics, diet, milk yield, manure) and agronomic sub-models (water and nutrient cycles, grass growth and crop yields) was used. This conceptual crop-livestock model follows the schematic representation of agricultural systems components and their interactions (Thorne, 1998) and can be seen as a stock-flow model (compartment model): the stocks are animals, crops, land, plant organic matter and livestock manure and the biomass circulating within the system are natural and cultivated fodders (including crop residue and mulch in conservation agriculture), crops, milk, animals, manure and plant nutrients.

Two models from the literature were combined, (i) GAMEDE (Vayssières et al., 2009), a whole-farm model, developed in Reunion Island dairy herds to dynamically represent the effect of management decisions on various sustainability indicators, such as milk and forage crop productivity, labour requirements, nitrogen balance, and (ii) FIELD (Tittonell et al., 2008), a dynamic summary model of the soil-crop system that captures essential interactions determining crop productivity in smallholder farming systems in the sub-Saharan area. The dairy module of GAMEDE was adapted to local smallholder dairy systems and the soil, crop and manure modules improved (FIELD). Other supplementary modules were added to integrate common family constraints (cash and food requirements, workforce availability, etc.) and input-output flows generated by pig and poultry activities.

\section{Data collection}

Four mixed farms with different structures (agricultural land size, dairy herd size) and management strategies (conservation agriculture practices) were used for calibration and validation steps (Table 1). An 'immersion' approach (living on and participating in the daily activities), inspired by the ethnographic approach, was adapted to access operational technical decisions and collect data frpm each farm on cropping and breeding practices, biomass allocation, manure management, social and economical constraints. Additional on-farm measurements were also needed for assessing fodder, soil and manure composition.

Table 1 Farm characteristics

\begin{tabular}{|c|c|c|c|c|c|c|c|c|}
\hline Farm & $\begin{array}{l}\text { Resource } \\
\text { endowment }\end{array}$ & $\begin{array}{l}\text { Agricultural } \\
\text { land (ha) }\end{array}$ & $\begin{array}{l}\text { Dairy cattle } \\
\text { (head) }\end{array}$ & $\begin{array}{c}\text { Permanent } \\
\text { workforce } \\
\text { (AWU) }\end{array}$ & Milk transaction & Diversification & $\begin{array}{l}\text { Conservation } \\
\text { Agriculture }\end{array}$ & $\begin{array}{l}\text { Off-farm } \\
\text { activities }\end{array}$ \\
\hline$A$ & poor & 6 & 1 & 3.6 & self-consumption & No & Yes & No \\
\hline B & medium & 4 & 7 & 6.9 & sale & barley & No & No \\
\hline C & rich & 11 & 4 & 9.1 & sale & pigs & Yes & Yes \\
\hline D & rich & 21 & 30 & 11.9 & transform & pigs, poultry & No & Yes \\
\hline
\end{tabular}

AWU: Agricultural workforce unit.

\section{Conclusions}

This model will ultimately be used to compare various strategies in biomass allocation and to identify key factors influencing the adoption of conservation agriculture (direct seeding mulch based cropping system) in smallholder farming systems in the Vakinankaratra region.

\section{References}

Douzet JM, Muller B, Scopel E, Albrecht A, Rakotoarisoa J and Rakotoalibera MH 2008. Terre malgache 26, 99-103.

Tittonell P, Corbeels M, van Wijk MT, Vanlauwe B and Giller KE 2008. Agronomy Journal 100, 1511-1526.

Thorne PJ 1998. Consultant's Report, Systems Analysis and Impact Assessment Project. ILRI, 68 p.

Thornton PK and Herrerro M 2001. Agricultural Systems 70, 581-602.

Vayssières J, Guerrin F, Paillat JM and Lecomte P 2009. Agricultural Systems 101, 128-138. 